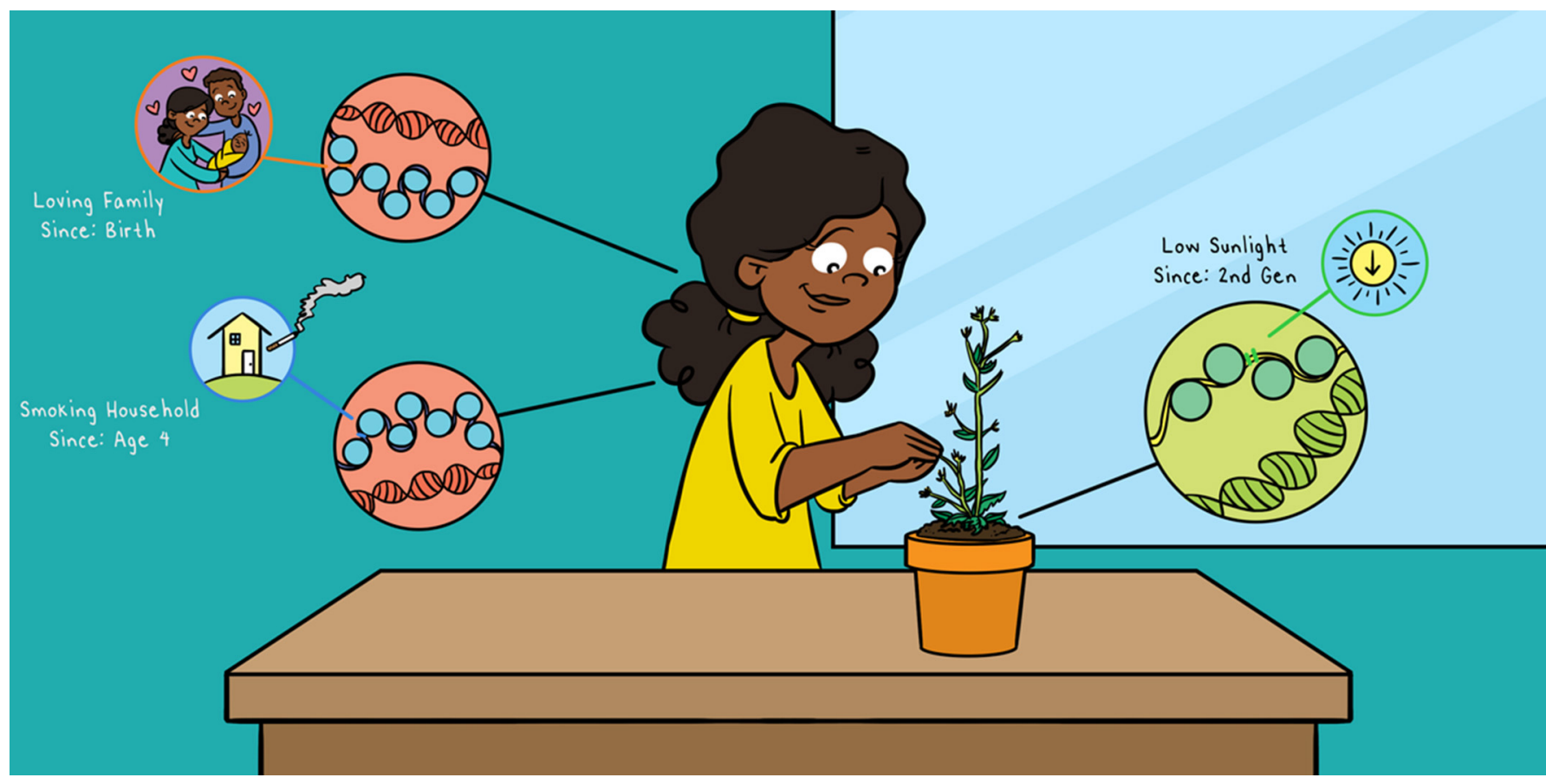

\title{
EPIGENETICS: SWITCHING GENES ON AND OFF
}

\section{Maria-Cecilia D. Costa ${ }^{1 *}$ and Frank Johannes ${ }^{1,2}$}

${ }^{1}$ Population Epigenetics and Epigenomics, Department of Plant Sciences, Technical University of Munich, Freising, Germany ${ }^{2}$ Institute for Advanced Study, Technical University of Munich, Garching, Germany

YOUNG REVIEWERS:

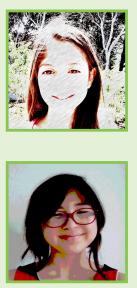

GIULIA

AGE: 11

KAYTLIN

AGE: 14
The DNA of a human cell has all the information necessary to produce more than 20,400 different proteins. This information is written in an amount of DNA that, if stretched end-to-end, would measure about one meter. You can imagine how challenging it is to keep all this information in an organized way. Other animals, bacteria, and plants face the very same challenge. The solutions to the problem of DNA organization found by cells include tightly packing the DNA and switching genes "on" and "off" as needed. The study of these switches is called epigenetics. Epigenetics is a fast-growing field of research that is changing our understanding of genetic information.

Do you know why our bodies have such different parts, like skin, eyes, and heart, even if almost all our cells have the same DNA? It is because different parts of our DNA are switched "on" and "off" in different cells! Would you like to understand this better? Then, let us take a close look at how the DNA is organized within the cells of the body. 
Figure 1

How the DNA is packed into the nucleus. The DNA is wrapped around sets of eight proteins called histones, forming structures called nucleosomes. All the nucleosomes together in the nucleus of a cell form what is called the chromatin.

\section{HISTONES}

Proteins associated with the DNA that package and organize it in the nucleus of cells.

\section{NUCLEOSOME}

Section of DNA wrapped around eight histones.

\section{CHROMATIN}

Structure made of DNA and proteins that enables the DNA to be packed into the nucleus.

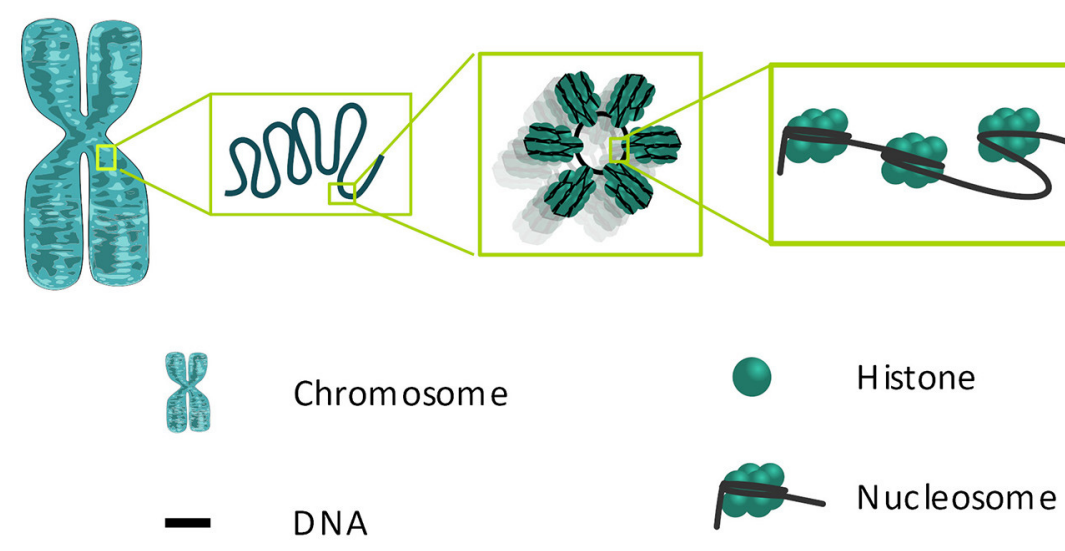

Figure 1

\section{HOW IS THE DNA ORGANIZED IN CELLS?}

Almost all the cells in the body have the very same DNA. This DNA is well-packed in super-tight coils in the nucleus. This is a great solution to solve the problem of fitting an awfully long molecule into the tiny space of the nucleus. The nucleus of a cell has a diameter only about one-tenth that of a human hair! Can you imagine fitting into a space that small an amount of DNA that, if stretched end-to-end, would measure about one meter long, in the case of humans?

In this packed form, the DNA is wrapped around proteins called histones, like the string around a yo-yo (Figure 1). The wrapping has a precise pattern, with $<2$ turns of DNA wrapped around a set of eight histones. It may sound weird that adding proteins makes the DNA more compact. But have you ever tried to store a garden hose? If so, you know that coiling it around a hose reel makes the job much easier. The DNA is wrapped around eight histones, which form a structure called a nucleosome. All the nucleosomes together form what is called the chromatin [1].

\section{HOW DO WE MAKE WELL-PACKED DNA ACCESSIBLE?}

Scientists estimate that the human genome has more than 20,400 genes which contain information for the formation of proteins. This sounds like a lot, but proteins are extremely important for the proper functioning and development of our bodies, so we need all these proteins. But we do not need all of them at the same time, and it would be difficult for a cell to deal with producing and managing so many types of protein simultaneously. Thus, only a few proteins are produced at the same time in a cell. This means that only a few genes are active (switched "on") at a time in any cell. The genes that are "on" will determine what that cell can do-the function of the cell. Some genes need to be active in more than one body part or cell type, while other genes are active only in specific cells. 
Figure 2

How chromatin is opened. A gene is switched "on" when the portion of chromatin where it is located "opens." This process involves proteins that add little chemical modifications to histones or to the DNA. The modifications cause the histone to slide on the DNA or cause the DNA to unwrap from the histone, allowing the chromatin to open and the information on the gene to be read.

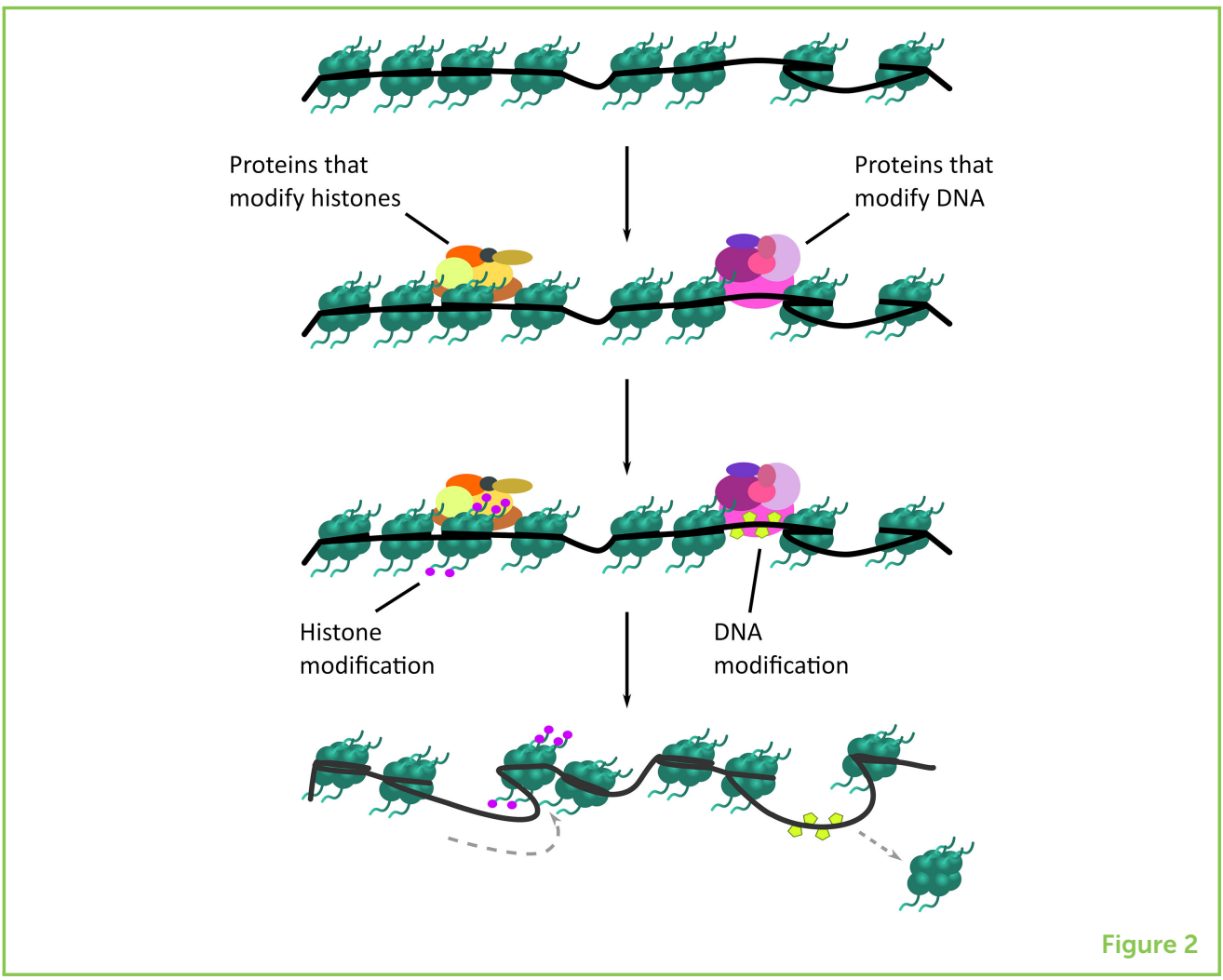

Well-packed DNA, wrapped tightly around histones, is not accessible to the cellular machinery that reads the information on the DNA and turns it into proteins. Imagine a book with some pages held together by a paper clip. You cannot read what is on those pages! They must be accessible to you before you can read them. The packaging of the DNA has the same effect. The portions of the chromatin that need to be read must become accessible, or open. The process of opening determines which genes will be active (where the chromatin is accessible) or inactive (where the chromatin is not accessible).

The process of opening the chromatin is important for the proper functioning of all cells. It involves protein complexes that make the DNA accessible to other proteins that can then read the information on the DNA or repair any damage. During chromatin opening, the protein complexes modify the DNA and the histones by adding little chemical groups (Figure 2). These chemical groups change how the nucleosomes interact with each other, affecting the structure of the chromatin in that region. The chemical groups can also weaken the interactions between histones and DNA. This makes the histones slide along the DNA or unwrap from the DNA, leaving the DNA accessible. Scientists are still trying to understand how the protein complexes select which nucleosomes to modify.

The state of the chromatin (if it is open or not) is constantly changing. After the fertilization of an egg, protein complexes from the parents guide the first modifications. In the early stages of development, the 


\section{EPIGENETICS}

Study of changes in the DNA that do not involve changes in the DNA sequence.

\section{EPIGENOME}

The complete description of all the epigenetic modifications to DNA and histones within the genome of an organism.

\section{EPIGENETIC} MODIFICATIONS

Reversible additions of chemical groups to the DNA or to the histones. These modifications can be transmitted to the next generation. embryo's DNA takes over. Then, the embryo's own DNA starts to control which portions of the chromatin will be open and closed.

The discovery of these modifications attracted the attention of scientists and an entire new field of research was born, called epigenetics. Epigenetics means "above" or "on top of" genetics. It refers to modifications that do not affect the sequence of the DNA itself and yet have a significant effect on which genes are active. The epigenome is the complete description of all these epigenetic modifications.

\section{HOW LONG DO THESE MODIFICATIONS LAST?}

Many factors influence the epigenome of an organism, such as age, environment, lifestyle, and health state. Epigenetic modifications caused by these factors can be "memorized" for long periods of time. When a cell divides, its epigenetic modifications are passed on to the next generation of cells. It is interesting that this situation is different in reproductive cells. Most epigenetic modifications are erased during reproduction. In animals, the modifications that persist only last for about one or two generations.

The epigenome of an organism is fluid, which means that it is constantly changing. It is shaped in response to stress, in ways that last from hours to months, years, or an entire life. For example, the epigenome of mice exposed to very stressful situations can change. These changes can affect their behavior. The mice can get depressed for days or several weeks [2]. People also show an influence of the environment on their epigenomes. For example, a person with a healthy diet or a life with little stress will have a different epigenome than someone with an unhealthy diet or a stressful life.

\section{DO PLANTS ALSO HAVE EPIGENOMES?}

You might be wondering if epigenetic changes only occur in animal cells. All organisms, including bacteria and even plants, have epigenetic changes. The study of epigenetics in plants has a long and rich history. The diversity of ways that plants modify their epigenomes is remarkable. Plants are masters of epigenetic modification! As they are unable to move to escape their surroundings, plants must cope with all sorts of natural conditions. Epigenetic modifications help plants to adapt to these conditions.

In plants, epigenetic modifications can persist for many generations. This is fascinating for scientists! They wonder if inheriting these modifications contributes to plant diversity and evolution. Or maybe the modifications help plants to adapt to new conditions. Maintaining epigenetic modifications might help plant populations have enough 
Figure 3

An epigenetic experiment with plants. Scientists crossed two Arabidopsis plants with identical DNA sequences but different epigenomes. The plants generated by this cross self-fertilized for many generations and maintained the epigenetic differences. These plants were also different from each other in certain traits, such as height, time taken to flower, and tolerance to salt in the soil.

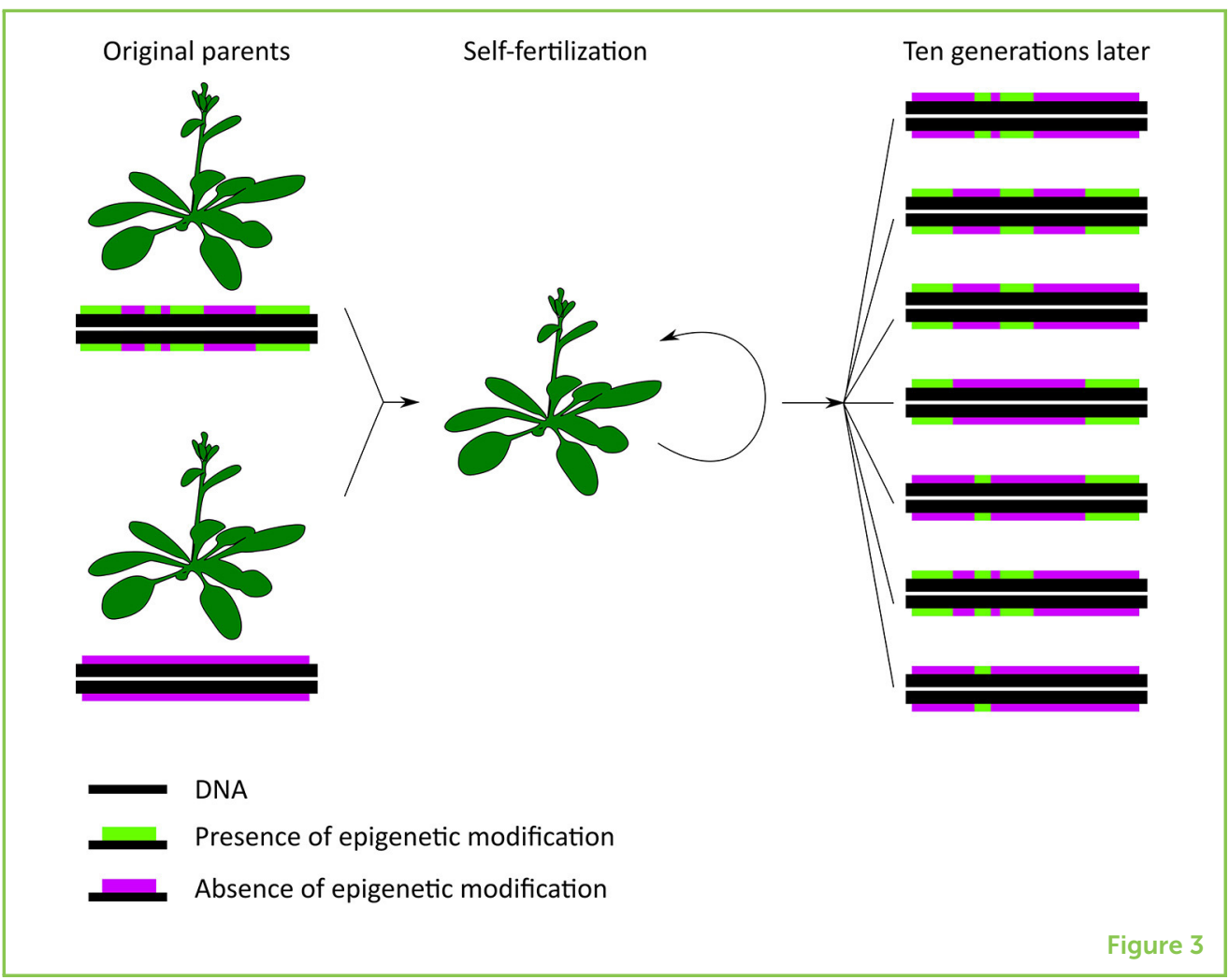

time to explore how each modification affects the number of seeds that they produce, for example.

\section{PLANT EPIGENETICS AND STRESS}

Plant scientists are using a plant called Arabidopsis to answer many important questions about epigenetics, such as how epigenetic changes are generated and how they are inherited. Arabidopsis is ideal for this. It grows quickly -it takes $<3$ months to complete one full growth cycle, from being a seed to producing seeds. This plant can self-fertilize, meaning that the pollen of one flower can pollinate the same flower that produced it.

In one experiment, scientists tested how many generations epigenetic changes last. They crossed two Arabidopsis plants that had identical DNA sequences but different epigenomes (Figure 3). They took the plants generated by this cross and self-fertilized them for many generations. After 10 generations, the epigenomic differences were still present! Also, inherited epigenetic changes caused the plants to be different from each other in certain traits. For example, some plants were taller, flowered earlier, or were more tolerant to salt in the soil $[3,4]$. From the results of this and similar experiments, scientists think that epigenetics are important in plant diversity and evolution. This knowledge can be used to make better crops! Many possibilities are being explored. Exciting times! 


\section{APPLICATIONS OF EPIGENETIC STUDIES}

Epigenetic studies have many applications. They explain variations between organisms and their responses to the environment. They help us to understand how nature influences variations in shape and behavior. They explain how these variations pass on from one generation to the next. Now you know that epigenetics can explain how the parts of our bodies are so different from each other. Epigenetics may help to predict the impact of the weather on crop yield. Plant breeders can use knowledge of epigenetics to develop crop varieties that are more resistant to stresses. Epigenetics can explain the origin, growth, and spread of certain types of cancer. Cancer epigenetics can improve cancer diagnosis and treatment. Epigenetics can also offer insights on how people respond in different ways to the same treatment for certain diseases. The number of applications is continually growing and is likely to continue to influence our lives in many beneficial ways!

\section{ACKNOWLEDGMENTS}

The authors wish to thank the Alexander von Humboldt - Stiftung, Bonn, Germany, for its financial assistance through a research grant to $\mathrm{M}-\mathrm{CC}$.

\section{REFERENCES}

1. Annunziato, A. 2008. DNA packaging: nucleosomes and chromatin. Nat. Educ. 1:26.

2. Sun, H. S., Kennedy, P. J., and Nestler, E. J. 2013. Epigenetics of the depressed brain: role of histone acethylation and methylation. Neuropsychopharmacology 38:124-37. doi: 10.1038/npp.2012.73

3. Cortijo, S., Wardenaar, R., Colomé-Tatché, M., Gilly, A., Etcheverry, M., Labadie, $\mathrm{K}$., et al. 2014. Mapping the epigenetic basis of complex traits. Science 343:1145-8. doi: 10.1126/science.1248127

4. Kooke, R., Johannes, F., Wardenaar, R., Becker, F., Etcheverry, M., Colot, V., et al. 2015. Epigenetic basis of morphological variation and phenotypic plasticity in Arabidopsis thaliana. Plant Cell 27:337-48. doi: 10.1105/tpc.114.133025

SUBMITTED: 21 April 2020; ACCEPTED: 04 December 2020;

PUBLISHED ONLINE: 23 December 2020.

EDITED BY: Ester Dias, University of Porto, Portugal

CITATION: Costa M-CD and Johannes F (2020) Epigenetics: Switching Genes On and Off. Front. Young Minds 8:554136. doi: 10.3389/frym.2020.554136 


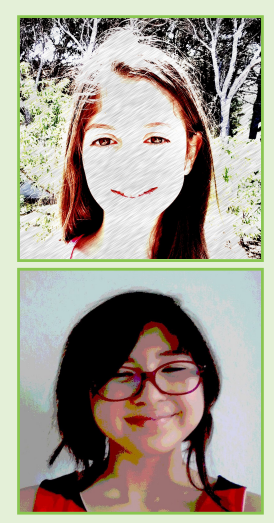

CONFLICT OF INTEREST: The authors declare that the research was conducted in the absence of any commercial or financial relationships that could be construed as a potential conflict of interest.

COPYRIGHT @ 2020 Costa and Johannes. This is an open-access article distributed under the terms of the Creative Commons Attribution License (CC BY). The use, distribution or reproduction in other forums is permitted, provided the original author(s) and the copyright owner(s) are credited and that the original publication in this journal is cited, in accordance with accepted academic practice. No use, distribution or reproduction is permitted which does not comply with these terms.

\section{YOUNG REVIEWERS}

\section{GIULIA, AGE: 11}

I am 11 years old and the next autumn I will be a first-year secondary school student. In my free time I practice synchronized swimming. I like reading and traveling and when I have the opportunity I prefer to stay in contact with nature.

\section{KAYTLIN, AGE: 14}

I am a first-year highschool student that likes to travel and explore different cultures and things. In my free time I read, do martial arts, teach myself Japanese, or let my creativity run loose by writing stories, drawing, or taking pictures.

\section{AUTHORS}
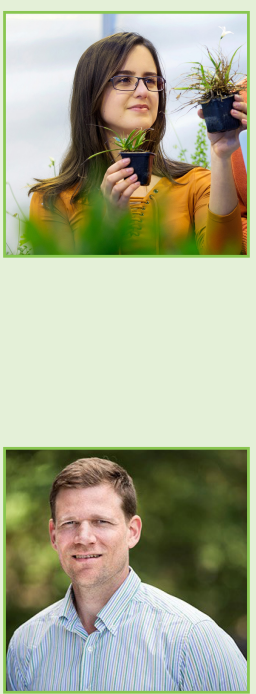

\section{MARIA-CECILIA D. COSTA}

Maria-Cecilia Costa loves plants. During her studies to become a biologist, she stumbled upon seeds that could not be stored (unlike most seeds that we know). These seeds led her to the fascinating world of plants that survive and thrive in harsh environments. Her work focuses in understanding how plants respond to their environment. She aims at contributing to the development of crop plants that are more drought tolerant. These crops are necessary to improve the lives of small farmers living in drought prone areas. *macecilia.costa@tum.de

\section{FRANK JOHANNES}

Frank Johannes is fascinated by how plants transmit changes in their DNA to their offspring. Curiously, the type of DNA changes that he studies are not DNA mutations as you may know from school, but rather changes in the way the DNA functions, for example if a gene is turned on or off. Scientists call this form of transmission "epigenetic inheritance." It turns out that plants are masters at this form of inheritance, and Frank spends most of his day trying to understand why. He does his work at the Technical University of Munich (Germany), but also likes to think about these questions during long hikes in the Alps. 